\title{
OnCHocerciasis in West Africa After 2002: A Challenge to take UP
}

\author{
HOUGARD J.-M.*, YAMEOGO L.** \& PHILIPPON B. ${ }^{* * *}$
}

\section{Summary:}

Initially planned for a 20 year life time, the Onchocerciasis Control Programme in West Africa (OCP) will have finally continued its activities for nearly three decades (vector control alone from 1975 to 1989 , then vector control and/or therapeutic treatment until 20021. Although onchocerciasis is no longer a problem of public health importance nor an obstacle to socioeconomic development in the OCP area, the control of this filariasis is not over because OCP never aimed at eradication, neither of the parasite (Onchocerca volvulus), nor of its vector (Simulium damnosum s.l.). In 2003, the eleven Participating countries of OCP will take over the responsibility of carrying out the residual activities of monitoring and the control of this disease. This mission is of great importance because any recrudescence of the transmission could lead in the long run to the reappearance of the clinical signs of onchocerciasis, if not its most serious manifestations. For epidemiological and operational reasons, and given the disparity in national health policies and infrastructures, the capacities of the countries to take over the residual activities of monitoring and control of onchocerciasis are very unequal. Indeed, the interventions to be carried out are very different from one country to another and the process of integrating the residual activities into the national health systems is not taking place at the same pace. This inequality among the countries vis-a-vis the challenges to be met does not, however, prejudge the epidemiological situation after 2002 whose evolution will also depend on the effectiveness of the provisions made before that date by OCP, then after 2002, by the Regional Office for Africa of the World Health Organization which is currently setting up a sub-regional multidisease surveillance centre.

KEY WORDS : onchocerciasis, insecticides, ivermectin, West Africa, post OCP period.

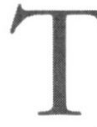
he Onchocerciasis Control Programme in West Africa (OCP) will cease its activities on

December 31, 2002, after 29 years of existence. No other public health programme ever benefited for so long from the logistical and financial support of the international community, the reason for this support

* IRD, 911, avenue Agropolis, BP 64501, 34394 Montpellier Cedex 5, France.

** Programme OMS/OCP, BP 549, Ouagadougou 01, Burkina Faso. *** IRD, 213, rue La Fayette, 75480 Paris Cedex 10, France. Correspondence : Jean-Marc Hougard, LIN/IRD, 911, avenue Agropolis, BP 64501, 34394 Montpellier Cedex 5, France. Tel.: + 33467043223 - Fax: + 33467542044
Résumé : L'ONCHOCERCOSE EN AFRIQUE DE L'OUEST APRÈS 2002 : UN DÉFI À RELEVER

Prévu initialement pour une durée de 20 ans, le programme OMS de lutte contre l'onchocercose en Afrique de l'Ouest (OCP) aura finalement poursuivi ses activités pendant près de trois décennies llutte antivectorielle seule de 1975 à 1989, puis lutte antivectorielle et/ou thérapeutique jusqu'en 2002). Bien que dans le périmètre d'OCP l'onchocercose ne soit plus un problème de santé publique ni un obstacle au développement socioéconomique, la lutte contre cette filariose n'en est pas terminée pour autant car l'OCP n'a jamais visé l'éradication, ni du parasite (Onchocerca volvulus), ni de son vecteur (Simulium damnosum s.l.). En 2003, les onze pays participants de l'OCP prendront la responsabilité des activités résiduelles de surveillance et de contrôle de cette maladie. La mission est d'importance car une recrudescence de la transmission aboutirait à terme à la réapparition des signes cliniques de l'onchocercose, sinon de ses manifestations les plus graves. Pour des raisons épidémiologiques et opérationnelles, et eu égard à la disparité des politiques et structures sanitaires nationales, les capacités des pays à prendre en charge les activités résiduelles de surveillance et de lutte contre l'onchocercose sont très inégales. Les interventions à mener sont en effet très différentes d'un pays à l'autre et le processus d'intégration des activités résiduelles dans les systèmes nationaux de santé ne s'opère pas au même rythme. Cette inégalité des pays face aux défis à relever ne préjuge toutefois pas de la situation épidémiologique après 2002 dont l'évolution dépendra également de l'efficacité des dispositions prises auparavant par l'OCP puis, après 2002, par le Bureau Régional pour l'Afrique de l'Organisation Mondiale de la Santé qui est en train de mettre en place une structure sous-régionale de surveillance pluripathologique.

MOTS CLÉS : onchocercose, insecticides, ivermectine, Afrique de l'Oues période post-OCP

being that the results obtained have always convinced the donors of the effectiveness of the control strategies used: vector control from 1975 to 1989 , then vector control and/or therapeutic control until 2002 (Molyneux, 1995). However, although human onchocerciasis is already no longer a problem of public health importance nor an obstacle to socio-economic development in all of the treated area, the control of this filariasis is not over. Indeed, OCP never aimed at eradication, neither of the parasite (Onchocerca volvulus) nor of its vector (Simulium damnosum s.l.) and onchocerciasis will still be present after 2002. Furthermore, high levels of endemicity compared to the expected situation persist here and there in the Pro- 
gramme area (Boatin et al., 1997), constituting actual residual foci of infection, even though onchocerciasis is no longer present there as a disease of public health importance. Lastly, it is probable that the dissemination of the parasite is facilitated by the human migrations which are becoming more and more intensive each year, in addition to the movements of great amplitude of blackflies with the help of the harmattan and monsoon winds

For these reasons, the concept of transfer of the residual monitoring and control activities from OCP to the Participating countries was put forward even before the launching of the operations (Anonymous, 1969). The Programme then attached increasing importance to this concept, both on the plans of its methods as of its actual implementation. As of 2003, the full and entire responsibility of these activities will fall on each of the eleven Participating countries. To take up this challenge, they will receive technical support from the Regional Office for Africa of the World Health Organization (WHO/AFRO) which is currently setting up in Ouagadougou (Burkina Faso), a sub-regional multidisease surveillance centre. As we shall see in this article, the extent of the task to be achieved is tremendous but unequally distributed among the different areas because OCP is leaving in heritage a great diversity of epidemiological situations.

\section{END 2002: A DISPARATE "HERITAGE"}

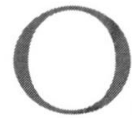
n December 31, 2002, onchocerciasis will have been eliminated as a disease of public heath importance throughout the OCP area. Nonetheless, the Programme will leave over the entire treated area a very heterogeneous situation on the epidemiological level. This can be explained, on one hand, by the diversity of the epidemiological facies encountered at the beginning of the operations and, on the other hand, by the diversity of the control activities undertaken during these three decades, both in their nature and in their duration. To that must be added the occurrence of some events which, although without any direct relationship to the Programme (socio-political unrest, demographic phenomena, town and country planning, agro-industrial development, etc), had some consequences on the course of the control operations. In order to establish, before the end of 2002, a detailed and comprehensive "stock taking of the situation" of onchocerciasis, OCP is constituting a data bank which should pool together all the information available on each village and river basin. This exercise will be extremely useful for the Participating countries which will be able to thus appraise, with maximum precision, the importance, nature and diver- sity of the residual surveillance and control activities. The brief "macro-typology" that we have produced here, at the beginning of 2002, gives a first outline of the estimated post-OCP situation with respect to onchocerciasis. It takes into account, for the whole of the "OCP area", the heterogeneity of the initial epidemiological situations as well as the diversity of the control activities, of the objectives aimed at and of their degree of effectiveness.

\section{AN HETEROGENEITY OF EPIDEMIOLOGICAL PATTERNS}

The clinical manifestations of onchocerciasis, due mainly to the accumulation of microfilariae in the dermis, appear primarily as skin and ocular lesions. In hyper-endemic savanna areas (prevalence higher than $60 \%$ and CMFL* from 10 to 15 microfilariae), these ocular complications can affect $20 \%$ of the population and the rate of blindness can exceed $10 \%$ (Remme et al., 1989). In forest areas, hyper-endemicity never leads to the desertion of river basins by man and only very rarely will it be accompanied by blindness (Dadzie et al., 1989). The skin lesions can however constitute, as in the savanna areas, and after several years of chronic infestation, a true problem of public health. These two different epidemiological facies, known as "the savanna" and "forest" forms, are probably related to the existence of at least two strains of $O$. volvulus, revealed through the use of specific DNA probes (Zimmerman et al., 1993). The "savanna" strain is transmitted, as its name indicates, in savanna areas, primarily by the savanna species of the $S$. damnosum complex while the "forest" strain is transmitted primarily by the forest species of the $S$. damnosum complex (Boakye, 1993). In the forest/savanna transition zones, the two strains of parasites cohabit with the different species of blackfly, thus producing an "intermediate" facies whose epidemiological features still remain to be specified. Research is under way to try to determine the existence of any specific adaptations between the vectors and the parasite strains and/or if there are any strains of O. volvulus with intermediate levels of pathogenicity in these transition zones (Toé et al., 1997).

\section{AN HETEROGENEITY OF INTERVENTIONS}

The strategy of control of onchocerciasis has from the inception of OCP, constantly evolved according to the advances made on onchocerciasis on one hand, and on its control on the other hand. From 1975 to 1989,

\footnotetext{
* Community MicroFilarial Load. It corresponds to the geometric mean of the number of microfilariae per skin snip in subjects aged twenty at least, including those who are not or no longer infected with microfilariae.
} 
in the absence of any drug usable for mass treatment, the control of the vector by spraying insecticides on its larval breeding sites was the only control strategy used. These treatments, centered on the most serious foci of onchocerciasis of the savanna type, aimed at stopping the transmission of the parasite for a time longer than the life-span of the adult worms in man, which is initially estimated to be about 18 years, then later brought down to 14 years (Plaisier et al., 1991). In 1987, the advent of ivermectin, a microfilaricidal drug making it possible to control onchocercal morbidity (Chippaux et al., 1995) considerably modified the control strategy. Since 1989, in the extension areas, the hypo- and meso-endemic foci of "savanna" onchocerciasis which were not treated with insecticides, as well as the hyper-endemic zones of "forest" onchocerciasis, were treated with ivermectin, only for controlling morbidity (Abiose et al., 2000). At the same time, for ethical (immediate relief of the populations) and strategic reasons (shortening by two years the theoretically required duration of the larviciding treatments - Plaisier et al., 1997), all of the forest/savanna transition zones which were treated with insecticides to control the transmission, were gradually put under chemotherapy with ivermectin to control the morbidity.

\section{AN HETEROGENEITY OF OBJECTIVES}

By the end of 2002, the areas treated only with insecticides will theoretically be "cleansed", unless they were re-contaminated by exogenous parasites during or after the control operations. Already, in most of the areas treated from 1975 to 1989, in the absence of any vector control and therapeutic treatment since 1989, the parasite is still undetectable in man or in the vector (Hougard et al., 2001), at least by the usual techniques of parasitological and entomological diagnosis. It will theoretically be the same for the areas treated both with insecticides and with ivermectin for twelve consecutive years (Plaisier et al., 1997). Lastly, in the areas treated with ivermectin only, the objective remains the control of morbidity, even if the long-term effect of this drug on microfilarial loads and the fecundity of the adult worms (Plaisier et al., 1995) should make it possible to increase the reduction of transmission. The treatments should therefore continue well beyond the end of the Programme if we take into account the results of recent simulations with the ONCHOSIM model which give at least 25 years of chemotherapy in certain foci, even much longer according to the degree of therapeutic coverage, the frequency of treatments or the mode of transmission (Winnen et al., 2002).

\section{AN HETEROGENEITY OF RESULTS}

In spite of the control operations, unexpected high levels of endemicity were recorded these last years in some localised zones of the Programme. Specific control interventions were instituted by OCP (Hougard et al., 1997) in collaboration with the Participating countries, so as to as fast as possible bring back the epidemiological trends to "normal". In some of these foci of infection, corrective measures produced the desired effect and the objectives were eventually achieved, despite a few years of delay compared to the initial schedule. This is the case for example of Kankéla, a village of Mali which was particularly subjected to reinvasions of infective blackflies until the installation of the extension zones in 1989 (Fig. 1). The prevalence was still $40 \%$ there in 1992, whereas it was practically nil in the other villages of this basin. This focus was finally cleansed thanks to reinforced distribution of ivermectin (twice a year) and the continuation beyond the initial cessation date, of vector control activities. This is also the case of the Dienkoa basin (Burkina Faso) where a premature reduction of vector control operations at the end of the 1980s caused a resumption of the infection. Effective corrective measures were then implemented since 1990 (combined control with ground larviciding and ivermectin treatment), and this focus should be cleansed very probably before end 2002. Finally, among the residual foci, we must set aside those in which the corrective control measures prove to be partially effective. These are either areas reinvaded by parasites coming from difficult or impossible to control areas, or from areas of exceptional difficulty of access, both by air and by land. Four foci of this type, all located in formerly hyper-endemic savanna areas, have been identified (Fig. 1). They are the foci located on the tributaries of the Oti at the border of Benin, Ghana and Togo, on the Pru in Ghana, on the Tinkisso at the border of Mali and Guinea, and on the Mafou in Guinea.

\section{EARLY 2003: A DIVERSITY OF RESIDUAL ACTIVITIES}

\begin{abstract}
A $s$ indicated below, such an heritage necessarily leads to a diversity of residual activities. These are monitoring activities in onchocerciasis freed areas, morbidity control activities in areas submitted to chemotherapy and specific interventions in the residual foci of infection.
\end{abstract}

\section{MONITORING ACTIVITIES}

Monitoring activities by the national teams have begun in the areas of OCP known as "cleansed" where the 


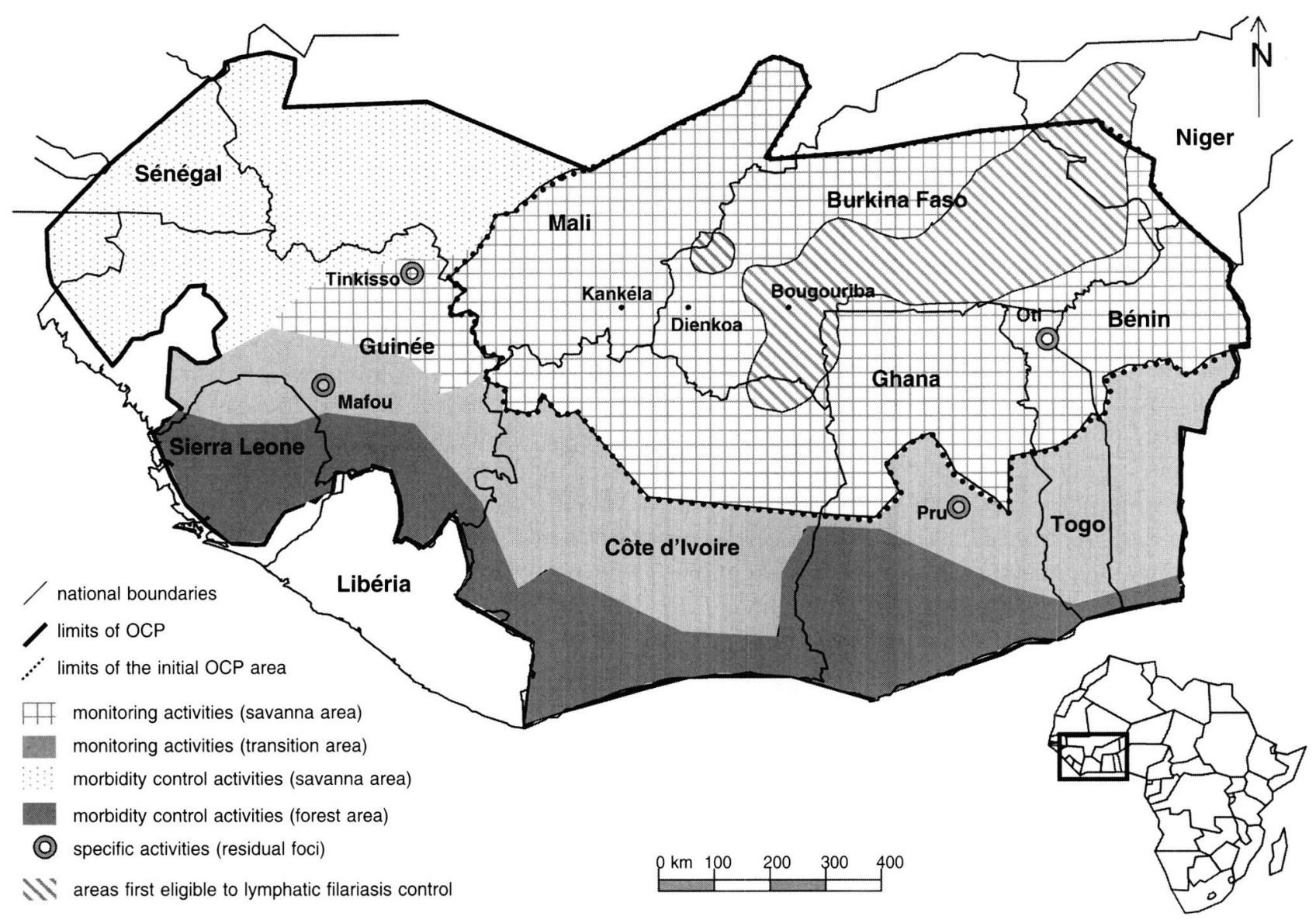

Fig. 1 - The onchocerciasis control strategies in 2003 with in the OCP aerea

epidemiological situation is satisfactory in spite of the cessation of vector control activities (no incidence, near zero prevalence, no transmission). These are the zones formerly treated with insecticides for the purpose of controlling the transmission, and as from 2003, it will be the majority of the areas having been subjected to vector control and chemotherapeutic treatment. The diagnostic tests of onchocerciasis already at the disposal of the national teams will be sufficiently sensitive and specific to make it possible to detect any resumption of the transmission and, if necessary, to control it by an adequate treatment with ivermectin. The countries will indeed have at least two complementary methods of detection of the parasite in man on the one hand, with the DEC patch test (Toé et al., 2000), which will replace the skin snip (Prost \& Prod'hon, 1978), and in the vector on the other hand, with the method of detection of the parasite by pool screening of blackflies (Yaméogo et al., 1999). In spite of the apparent simplicity of these monitoring activities, the absence of any parasitological manifestation of the disease and, a fortiori, of any clinical manifestation, is a factor of demotivation which can make difficult the application of these measures. The national health services, with support from the AFRO sub- regional multidisease surveillance centre, will therefore have to remain vigilant, more especially as these areas contained, in the beginning, the most severe foci of onchocerciasis.

\section{MORBIDITY CONTROL ACTIVITIES}

In the areas treated with ivermectin, the distribution of the drug will continue after 2002, for several more years, unless a macrofilaricide quickly becomes operationally available (Tagboto \& Townson, 1996; Langworthy et al., 2000). That is why chemotherapy will continue through an institutionalized strategy of Community Directed Treatment with Ivermectin (CDTI), already used by OCP and the countries of the African Programme for Onchocerciasis Control (Remme APOC, 1995). Its principle rests on the distribution of ivermectin by community members selected by the population itself and specially trained in the various activities related to the treatment (Diarra, 1998). The Programme will continue to provide, until the end of 2002, financial and technical support to the participating countries by helping them retrain all the players in CDTI, particularly the nurses of peripheral health centres and the Community directed distributors. These 
training and retraining activities will then be taken over after 2002 by the health staff, itself trained by the national, regional or district teams in charge of onchocerciasis control, with support from the AFRO subregional multidisease surveillance centre, as well as certain Non-Governmental Organizations (NGOs).

\section{SPECIFIC ACTIVITIES}

The residual foci of infection which will remain after 2002 will be mainly the responsibility of the Participating countries. Those for which the corrective measures seem to bear fruit should not pose any major problems, provided the countries can count on the technical and financial external support: bilateral sources, AFRO sub-regional multidisease surveillance centre, NGOs, private or multinational companies. However, these operations will have to be limited in time and to be relatively easy to implement. Higher therapeutic coverage, even ground larviciding treatments, can reasonably be considered, provided that the national teams are trained beforehand, as is the case for example for the Dienkoa focus. On the other hand, for the four residual foci where the corrective measures taken by OCP have remained partially ineffective, it will be more difficult to succeed where a vertical control programme has been less successful. Although they represent a tiny part of the entire treated Programme area, the existence of these foci constitutes a threat for the surrounding cleansed areas. The focus located on the tributaries of the Oti is probably the one of most concern. Located right at the border of the original Programme area, some of the villages of this focus still remain meso-endemic, even hyper-endemic in spite of the implementation, since 1998, of exceptional corrective measures (Anonymous, 2001) and in spite of more than 20 years of vector control by air, including combined vector control and ivermectin distribution over the last ten years.

\section{THE POST OCP ERA:}

\section{AN UNEQUAL CHALLENGE}

$\mathrm{T}$ The idea that the countries would in the long run assume the entire responsibility for the residual activities of monitoring and control of onchocerciasis was entertained even before the launching of OCP. The programme thus always devoted a significant part of its activities to the training of national staff, to the sensitisation of national authorities and the public, to the support of operational research and to the transfer of the data. In spite of all this, as we have just seen, for epidemiological and operational reasons, and given the disparity of national health policies and infrastructures, the capacities of the countries to take over the residual activities of control of onchocerciasis remain unequal. Indeed, the nature of the residual activities of monitoring and control of onchocerciasis differs considerably from one country to another. Some countries, like Côte d'Ivoire for example, will have to make sure that CDTI activities (in the forest zones) and monitoring (in the rest of the country), are carried out under satisfactory conditions. Other countries, like Togo, in addition to the activities of monitoring and control of morbidity, will be confronted with some residual foci of infection whose control poses serious problems at the present time. Indeed, after the closing of $\mathrm{OCP}$, the Participating countries will count on only ivermectin distribution as a means of control of onchocerciasis: vector control operations by air are always extremely expensive and those from the ground, apart from some special cases (quite isolated foci, supplement to aerial treatments), are more intended to control blackfly nuisance than transmission (Hougard \& Sékétéli, 1998). Another source of inequalities also lies in the process of integration of the residual activities in the national health systems. It is taking place indeed at different paces according to the countries because it depends on a great number of factors such as the level of priority granted to onchocerciasis, the state of the health infrastructures and other sectors of health development, the effectiveness of early warning and treatment mechanisms, the availability of trained specialists, the number and dynamism of the non-governmental organizations or still the constraints related to the implementation and evaluation of CDTI. Lastly, another source of inequality lies in the fact that several countries of the OCP area (Benin, Burkina Faso, Ghana and Togo) will soon benefit from a bi-therapy with ivermectin and albendazole within the framework of the WHO programme of elimination of lymphatic filariasis (Elimination of Lymphatic Filariasis: ELF Ottesen, 2000). The areas of geographic overlap of these two filariases are sizeable (Fig. 1), which will indirectly facilitate the task of these countries in the epidemiological monitoring and control of onchocerciasis.

\section{CONCLUSION}

$\mathrm{I}$ follows from the preceding that after 2002 onchocerciasis will not be anymore a disease of public health importance in the entire OCP area. The capacity "to manage" the risk of onchocerciasis will constitute a real challenge for both the Participating countries and the AFRO sub-regional multidisease surveillance centre. In spite of the inequality of the tasks to be carried out, this could by no means prejudge the 
evolution of the situation in each country. Indeed, in the areas where the residual activities of surveillance of onchocerciasis are limited to simple monitoring activities, a durable absence of any infection can be a factor of demotivation which can lead to an unsuspected resumption of the transmission. Conversely, the countries which contain the most alarming residual foci are the subject of very close attention from the Participating countries and donors, as well as the international scientific community, aware as they are of the medical, social and economic consequences which a recrudescence of onchocerciasis in West Africa could have. From being difficult to tackle at the sole national level, this challenge will become more surmountable from the moment that scientific, logistical, material and/or financial support could be brought forward. Such is the case for example of the tributaries of the Oti which constitute perhaps at the present time one of the most important subjects of concern and reflexion because of the complexity of the epidemiological situation there.

\section{REFERENCES}

Abiose A., Homeida M., Liese B., Molyneux D. \& Remme H. Onchocerciasis control strategies. The Lancet, 2000, 356, 1523.

ANONYMOUS. Joint USAID/OCCGE/WHO technical meeting on the feasibility of onchocerciasis control, Tunis, 1-8 July 1968. Mimeographed document WHO/ONCHO/69.75, 1969, Geneva: WHO

AnONymous. Rapport de la réunion sur les recherches opérationnelles et stratégies de l'OCP, Ouagadougou, 9-11 avril 2001, Mimeographed document WHO/OCP/EAC22.2, 2001, Ouagadougou: WHO.

Anonymous. Report of the twenty-second session of the Expert Advisory Committee of the Onchocerciasis Control Programme in West Africa. Ouagadougou, 4-8 June 2001. Mimeographed document WHO/OCP/EAC22, 2001, Ouagadougou: WHO

BOAKYE D.A. A pictorial guide to the chromosomal identification of members of the Simulium damnosum Theobald complex in West Africa with particular reference to the Onchocerciasis Control Programme area. Tropical Medicine and Parasitology, 1993, 44, 223-244.

Boatin B., Molyneux D.H., Hougard J.-M., Christensen O.W., Alley E.S., Yaméogo L., Sékétélu A. \& Dadzie K.Y. Patterns of epidemiology and control of onchocerciasis in West Africa. Journal of Helminthology, 1997, 71, 91-101.

Chippaux J.-P., BoussinesQ M. \& Prod'hon J. Apport de l'ivermectine dans le contrôle de l'onchocercose. Cahiers Santé, 1995, 5, 149-158.

Dadzie K.Y., Remme J., Rolland A. \& Thylefors B. Ocular onchocerciasis and intensity of infection in the community. II. West African rainforest foci of the vector Simulium yahense. Tropical Medicine and Parasitology, 1989, $40,348-354$
Diarra T. La distribution et le traitement par l'ivermectine sous directives communautaires. Cabiers Santé, 1998, 8, 81-83.

Hougard J.-M., Alley E.S., Yaméogo L., Dadzie K.Y. \& Boatin B.A. Eliminating Onchocerciasis after 14 years of vector control: a proved strategy. The Journal of Infectious Diseases, 2001, 184, 497-503.

Hougard J.-M. \& SÉKÉTÉlI A. Combating onchocerciasis in Africa after 2002: the place of vector control. Annals of Tropical Medicine and Parasitology, 1998, 92, S165-S166.

Hougard J.-M., Yaméogo L., SéKétéli A., Boatin B. \& Dadzie K.Y. Twenty-two years of blackfly control in the Onchocerciasis Control Programme in West Africa. Parasitology Today, 1997, 13, 425-431.

Langworthy N.G., Renz A., Mackenstedt U., Henkle-Duhrsen K., de Bronsvoort M.B., Tanya V.N., Donnelly M.J. \& Trees A.J. Macrofilaricidal activity against the filarial nematode Onchocerca ochengi: elimination of Wolbachia prevedes worm death and suggests a dependent relationship. Philosophical Transactions of the Royal Society of London, Series B, Biological Sciences, 2000, 267, 10631069.

Molyneux D.H. Onchocerciasis Control in West Africa: current status and future of the Onchocerciasis Control Programme. Parasitology Today, 1995, 11, 399-402.

OTTESEN E.A. The global programme to eliminate lymphatic filariasis. Tropical Medicine and International Health, 2000, 5, 591-594

Plaisier A.P., Alley E.S., Boatin B.A., Van Oortmarssen G.J., Remme H., De Vlas S.J., Bonneux L \& Habbema J.D. Irreversible effects of ivermectin on adult parasites in onchocerciasis patients in the Onchocerciasis Control Programme in West Africa. The Journal of Infectious Diseases, 1995, 172, 204-210.

Plaisier A.P., Alley E.S., Van Oortmarssen G.J., Boatin B.A. \& HABBEMA J.D.F. Required duration of combined annual ivermectin treatment and vector control in onchocerciasis Control Programme in West Africa. Bulletin of the World Health Organization, 1997, 75, 237-245.

Plaisier A.P., Van Oortmarssen J., Remme J. \& Habbema J.D.F. The reproductive lifespan of Onchocerca volvulus in West African savanna. Acta Tropica, 1991, 48, 271-84.

Prost A. \& Prod'hon J. Le diagnostic parasitologique de l'onchocercose. Revue critique des méthodes en usage. Médecine Tropicale, 1978, 38, 519-32.

Remme J.F.H. The African Programme for Onchocerciasis Control (APOC): preparing to launch. Parasitology Today, 1995, 13, 418-424.

Remme J., Dadzie K.Y., Rolland A. \& Thylefors B. Ocular onchocerciasis and intensity of infection. I. West African savanna. Tropical Medicine and Parasitology, 1989, 40, 340-347.

TAgBoto S.K. \& Townson S. Onchocerca volvulus and O. lienalis: the microfilaricidal activity of moxidectin compared with that of ivermectin in vitro and in vivo. Annals of Tropical Medicine and Parasitology, 1996, 90, 497-505.

Tó L., Adjami A.G., Boatin B.A., Back C., Alley E.S., Dembele N., Brika P.G., Pearlman E. \& Unnasch T.R. Topical 
application of diethylcabamazine to detect onchocerciasis recrudescence in West Africa. Transactions of the Royal Society Tropical Medicine and Hygiene, 2000, 94, 1-7.

Tó L., Tang J., Back C., Katholi C.R. \& Unnasch T.R. Vectorparasite transmission complexes for onchocerciasis in West Africa. The Lancet, 1997, 349, 163-166.

Winnen M., Plaisier A.P., Alley E.S., Nagelkerke N.J.D., Van Oortmarssen G., Boatin B.A. \& Habbema J.D.F. Ivermectin mass treatments for onchocerciasis control: can they eliminate infection in Africa? Bulletin of the World Health Organization, 2002, accepté pour publication.

Yaméogo L., Toé, L., Hougard J.-M., Boatin B. \& Unnasch T. Pool screen Polymerase Chain Reaction for estimating the prevalence of Onchocerca volvulus infection in Simulium damnosum sensu lato: Results of a field trial in an area subject to successful vector control. American Journal of Tropical Medicine and Hygiene, 1999, 60, 124-128.

Zimmerman P.A., Toé L. \& Unnasch T.R. Design of Onchocerca DNA probes based upon analysis of a repeated sequence family. Molecular and Biochemical Parasito$\log y, 1993,58,259-268$.

Reçu le 18 mars 2002

Accepté le 2 avril 2002 